\title{
Performance Characteristics of Rotating Biological Contactors Within Two Commercial Recirculating Aquaculture Systems
}

\author{
S. D. Van Gorder*1, J. Jug-Dujakovic ${ }^{2}$ \\ ' Fresh-Culture Systems, Inc. \\ 630 Independent Road \\ Breinigsville, PA 18031 USA \\ ${ }^{2}$ Atlantis Aquaculture Group \\ 840 Broad Street \\ Emmaus, PA 18049 USA \\ *Corresponding author: altaqua@ptd.net
}

Keywords: Filtration, recirculating aquaculture system, rotating biological contactors, fixed-film bioreactor, nitrification

\section{ABSTRACT}

Biological filtration is a critical determinant in the process train design of a recirculating aquaculture system. In addition to the mechanical and biological efficiency of the biofilter itself, this process must be co-developed with the various interrelated technologies involved in water-quality control. This study describes the performance of rotating biological contactors as an integral part of two commercial closed recirculating fish production systems. Data is presented from replicated systems employing paddlewheel-driven rotating biological contactors.

The RBC is a robust fixed-film bioreactor demonstrating excellent operational attributes in recirculating aquaculture systems. The efficiency of the RBC as biofilter is defined according to its mechanical and biological performance characteristics. In addition to highly efficient nitrification of ammonia under heavy feeding conditions $\left(1.21 \mathrm{~g} / \mathrm{m}^{2} / \mathrm{day}\right)$, the $\mathrm{RBC}$ has significant influence on the control of secondary water-

International Journal of Recirculating Aquaculture 6 (2005) 23-38. All Rights Reserved (C) Copyright 2005 by Virginia Tech and Virginia Sea Grant, Blacksburg, VA USA 
quality and hydraulic considerations affecting the overall design and performance of the system. RBCs off-gas carbon dioxide, providing a level of $\mathrm{pH}$ control, a significant benefit in closed recirculating systems. Additional data is presented for carbon dioxide sparging efficiency, and the capacity for versatile hydraulic loading and low-head operation.

This paper also provides a practical comparison of RBC design and performance considerations with other biofilter options, including the effects of design on the mechanical reliability, energy requirements, and spatial efficiency of this biofiltration system.

\section{INTRODUCTION}

\section{Management of Nitrogenous Wastes - Biofilter Design Priorities}

Ammonia, the principal nitrogenous waste of fish, results from the digestion of protein, and is therefore generated in proportion to the levels of feed administered. In recirculating aquaculture systems, without significant dilution, ammonia must be removed by a two-step process called nitrification. Nitrifying bacteria, concentrated on the biofilter media surfaces, convert ammonia to nitrite and then to relatively harmless nitrate. Nitrate is allowed to accumulate to levels determined by the amount of dilution (defining the \% recirculation rate of the recycle system). Since both ammonia and nitrite are toxic to fish, their levels must be managed through the efficient design of biofiltration systems.

Biological filters must provide adequate surface area for the growth of nitrifying bacteria. Nitrosomonas and Nitrosospira convert ammonia to nitrite, and Nitrobacter and Nitrospira convert nitrite to nitrate. The water containing the dissolved waste must be brought into contact with the surface area supporting these populations of bacteria. The health of the bacterial film is affected by the availability of oxygen, the temperature, the organic loading, the $\mathrm{pH}$, and the alkalinity of the water, all of which must be managed in tandem with the requirements of the fish. During operation, the filter cannot be permitted to clog with fish wastes or the sloughing bacterial biomass. The filter media must therefore be self-cleaning, or involve manual or automated management technologies to remain unclogged.

\section{Ammonia}

Ammonia dissolved in the water exists as two compounds in equilibrium: ionized ammonium $\left(\mathrm{NH}_{4}^{-}\right)$and un-ionized ammonia $\left(\mathrm{NH}_{3}\right)$. While 
un-ionized ammonia is extremely toxic to fish, the ionized portion is relatively harmless. The proportion of each is determined primarily by the $\mathrm{pH}$ of the water. The higher the $\mathrm{pH}$, a measure of hydrogen ion $\left(\mathrm{H}^{+}\right)$concentration, the higher the proportion of un-ionized ammonia. Therefore, $\mathrm{pH}$ control of the culture water is crucial to maintenance of acceptable levels of ammonia, and provides an opportunity for a wider range of water quality management parameters. Biofilters nitrify ammonia much more efficiently as the substrate concentration (level of total ammonia in the water) increases. Therefore, biofilter efficiency can be optimized by maintaining total ammonia at somewhat elevated levels, but at a pH which maintains the levels of un-ionized ammonia below that considered detrimental to the fish species being cultured. For example, with TAN (total ammonia nitrogen) levels at $3.0 \mathrm{mg} / \mathrm{l}$ and a $\mathrm{pH}$ of 7.2 , the level of un-ionized ammonia $\left(\right.$ at $26^{\circ} \mathrm{C}$ ) is only $0.029 \mathrm{mg} / \mathrm{l}$, below the level of significant toxicity for many species. To maintain TAN levels at $1.0 \mathrm{mg} / \mathrm{l}$ would require a biofilter with three times the capacity, at a significant and unnecessary additional expense.

\section{Nitrites}

Nitrite $\left(\mathrm{NO}_{2}\right)$ is the intermediate product of nitrification and the biofiltration process. Under normal operating conditions, biofiltration should maintain a balance of nitrifying bacterial populations which will control both ammonia and nitrite levels. There are times when an imbalance in the nitrification efficiency of the biofilter may result in transient elevations in levels of nitrite in the culture water. This can usually be accommodated since the toxicity of nitrite is significantly reduced by the presence of chloride ions. By maintaining a minimal level of salt $(\mathrm{NaCl})$ in the water $(<1 \mathrm{ppt})$, it is possible to reduce the potential toxicity of nitrites. Rotating biological contactors have been used successfully in conditions of freshwater to full seawater concentrations of salt.

\section{Rotating Biological Contactors (RBCs)}

Biofilter design must take into account all of the stated water-quality management criteria, as well as considerations of space and cost efficiency. A rotating biological contactor or biodisc filter is a fixed film bioreactor composed of circular plates aligned on a central axle. The filter is usually staged within a flooded containment plumbed for a prescribed flow of water, with approximately half of the disc surfaces submerged, 
and half exposed to the air. The discs are rotated slowly to alternately expose the biologically active media to the water carrying the nutrients (the nitrogenous wastes of the fish) and to the air, essentially providing an unlimited source of oxygen to the bacteria. The shear force on the surface of the discs as it passes through the water continuously sloughs senescent and thickening bacterial biomass, thereby maintaining a healthy biofilm.

Various mechanical designs of this biofilter configuration have been considered for recirculating aquaculture systems for decades (Lewis and Buynak 1976). The RBC has been shown to outperform many other fixed-film configurations applied to fish culture systems (Van Gorder and Fritch 1980; Miller and Libey 1984, 1985; Rogers and Klemetson 1985). Wheaton et al. (1994) number the inherent advantages of RBCs for aquaculture as:

1) the RBC is self-aerating, providing oxygen to the attached biofilm,

2) the RBC is a low-head device minimizing pumping energy needs,

3) the RBC is non-clogging due to shearing of loose biofilm caused by the rotation of the media through the water, with self-maintenance of an active biofilm, and

4) once established, RBC performance is reliable and resistant to sudden failures.

However, Wheaton also observes that almost all problems with RBCs "fall into the category of mechanical failures." Most reviews of RBCs disclose that failures with the drive motor, linkage, chain drive, bearings, breaking shafts, and the disassociation of the media from the shaft are problems with most RBCs designed for both municipal and aquacultural purposes.

Hochheimer and Wheaton (1998) state that RBCs are "generally quite stable in operation, have a high ammonia removal efficiency compared to some other biofilters, and operate with very little head loss." However, they indicate that "their primary disadvantage is that they require a power source to turn them, and mechanical breakdown can be a problem, particularly with a poorly designed unit." Timmons et al. (2001) affirm that RBCs "require little hydraulic head, have low operating costs, provide gas stripping, and can maintain a consistently aerobic treatment environment." They "also tend to be more self cleaning than static 
trickling filters." But they state that "the main disadvantages of these systems are the mechanical nature of their operation and the substantial load on the shaft and bearings."

As noted, RBCs have various attributes, some positive and some negative, and can be compared with other biofilter designs in each of these categories. The following study of rotating biological contactors in commercial aquaculture applications illustrates these comparisons, and the consequences of the design of the biofilter on its integration with the other system components within an efficient recirculating aquaculture system. This study will consider the performance characteristics of RBCs within two commercial recirculating aquaculture systems in eastern Pennsylvania. All observations were made and data collected under fully operational, commercial production conditions during the culture of hybrid striped bass.

\section{RBC Design - Mechanical Durability and Reliability}

The RBC units evaluated in this study are manufactured by Fresh-Culture Systems, Inc. (Breinigsville, PA, USA). They are categorized as "floating/ air-driven/rotating biological contactors. The units are comprised of flat and corrugated sheets mounted on a central PVC shaft. Appropriately positioned high-density styrofoam flotation provides the filters with neutral buoyancy, which allows for the near frictionless rotation of the central shaft within a guiding channel at each end of a fiberglass stage. Rotation is affected by the injection of air below, and/or water onto, a centrally placed paddlewheel. Using spokes and rigorous attachment methods, the media is secured tightly to the rotating shaft and central paddlewheel. The present design eliminates all requirements for a drive motor, chain, pillow blocks, or weight-supporting center shaft. The design of the RBC as a floating unit, with its weight supported by the water column rather than against the axle and pillow blocks, results in very little resistance to the rotation of the biofilter within the staging unit.

Traditionally designed RBCs must maintain the drive motor, and a direct-drive central axle, above the level of the water, thereby achieving only about $40 \%$ submergence of the active biofilter media. The present $\mathrm{RBC}$ design allows for a full $50 \%$ submergence (at full acclimation weight) through the integration of the appropriate level of buoyancy. This optimizes the alternate flooding of the media and exposure to the air. 


\section{Low-Energy Operational Characteristics}

The energy required to maintain rotation of these $\mathrm{RBCs}$ is almost negligible. A low-pressure regenerative air blower provides the minimal volume of air (approximately $2.0 \mathrm{cfm}$ directed below the paddlewheel) necessary to maintain rotation of the $186 \mathrm{~m}^{2}$ and $557 \mathrm{~m}^{2} \mathrm{RBCs}$.

Considering this, a single 1HP blower (at 30 inches of water pressure) will supply enough air for the rotation of $32 \mathrm{RBCs}$. Considering the use of 18 $\mathrm{kwh}$ of energy per day to accomplish this, at $\$ 0.08 / \mathrm{kwh}$, and a total daily expense of about $\$ 1.44$, then each RBC would use about $\$ 0.05 /$ day to provide rotation.

For redundancy, an additional torque was applied to the paddlewheel of the large $930 \mathrm{~m}^{2}$ units being considered in this study, by the application of $\sim 15 \mathrm{lpm}$ of water flow over the paddlewheel. This minimal volume was diverted for biofilter rotation from the total 1,800 lpm (average) of flow through each of the biofilters. Under low-head pumping conditions, the application of a $2.0 \mathrm{HP}$ pump to provide $900 \mathrm{lpm}$ of flow will cost approximately $\$ 2.88 /$ day. Diverting $1.7 \%$ of this flow for biofiltration rotation represents a cost of about $\$ 0.05 /$ day. Therefore the total estimated cost for achieving rotation of the larger $\mathrm{RBC}$, using both air and water, costs about \$0.10/day. Either the air or water flow alone will maintain the rotation of these units, the weight of which, at full acclimation and loading, is estimated at over $700 \mathrm{kgs}$.

\section{Unencumbered Hydraulic Loading}

The hydraulic design of a biofilter will demonstrate an inherent capacity to allow a flow of water to pass through it, a feature that is usually dependent on the physical characteristics of the media. The blockage of flow over time varies with the quality of the clarification systems and the level of biomass loading, with the resulting resistance to flow adding to the system's additional energy requirements.

The RBC provides no restriction to the flow of water through the biofilter, even under conditions of heavy biomass loading and full acclimation, and can accommodate very high flow rates without requiring additional energy. When co-developed with associated unit processes, this provides for potential low-energy pumping options.

\section{Low-Head Operation}

Efficient system integration requires the determination of the proper 
flow rate of water through the biofilter to provide for enough passes of the culture water daily to maintain the ammonia at desired levels, while minimizing the energy consumption requirements. The RBC, if properly plumbed using sufficiently sized influent and effluent pipes, provides unimpeded flow characteristics. The energy costs for pumping are minimized by operating with the biofilter water levels below tank water levels. Filters which must be elevated above the tank water level, including trickling and many fluidized media filters, must expend additional energy to elevate the pumped water.

Another measure of the energy costs involved in the operation of a biofilter is the head pressure under which it must be operated. Filters with fine media through which large volumes of water must be pumped, such as sand or bead filters, require correspondingly high water pressures, and subsequently increased electrical costs to operate. With fluidized sand filters, additional energy must be expended to fluidize the media and to elevate the water within the mixing chamber. The fluidized media must be elevated sufficiently to prevent the sand from exiting the chamber with the flow of water.

Within the biofilter, the flow characteristics must also allow for the contact of all of the available media surface area with the circulated water, with an appropriate retention period within the biofilter containment for optimal nitrification efficiency. The design of the rotating biological contactor does not involve passing a volume of water through a media bed, but instead allows for the unimpeded movement of the concentrated surface area of the biofilter through the moving volume of water. There is no requirement for high-pressure flow, or potential for the disruption of biological films due to these high-pressure flows, as in bead and sand bed filters.

\section{Non-clogging Operation}

Filter design must also eliminate the potential for clogging, since the inability to transport the culture water to the full area of media supporting the bacteria renders it less effective. Clogging can occur as a result of an accumulation of solid wastes due to inadequate clarification, or if the biofilter itself is not self-cleaning. The natural life cycle of the bacterial population results in significant quantities of senescent autotrophic and heterotrophic bacterial biomass, which must be sloughed from the filter media continuously and transported to the clarification system. This requires a biofilter with the proper balance of surface area and void space, 
and a sufficient flow rate across the filter media to provide the necessary shearing force. RBCs provide an optimal surface and operational platform for this process, with the shearing force provided by sufficient rotational velocity (in the present design, $1.5 \mathrm{rpm}$ ).

\section{Self-Aerating Capacity}

Maintaining water quality within specific ranges of tolerance for the bacteria is critical to biofilter operation. A reduction in dissolved oxygen (DO) levels in the water passing through the biofilter will reduce the efficiency of nitrification. Levels must remain elevated above $2 \mathrm{mg} / \mathrm{l}$ (Wheaton et al. 1994) throughout the biofilter, or overall efficiency will suffer. The design of submerged biofilters must maintain adequate DO levels through filter aeration, optimal flow rate, and proper sizing of the filter, as well as by negating the possibility of clogging and the subsequent channeling of water through a reduced area within the biofilter.

As water moves through the media of submerged biofilters, dissolved oxygen levels are reduced by the Biological Oxygen Demand (BOD) of the bacterial populations to a point which subsequently reduces the nitrification efficiency of the biofilter. It is often necessary to aerate the water within the biofilter to maintain optimal nitrifying conditions. Timmons et al. (2001) provides a "rule of thumb" that for each gram of ammonia nitrified, 4.57 grams of oxygen are required to maintain the bacterial population. Unlike submerged biofilters, trickling filters and rotating biological contactors provide for an air/water interface at the surface of the bacterial film. These biofilters are thereby afforded an unlimited level of oxygen availability to the associated bacterial biomass. The RBC uses atmospheric oxygen, resulting in optimal conditions of nitrification, without additional costs for supplemental aeration or oxygenation, and without appropriating the dissolved oxygen being made available to the fish populations.

\section{Carbon Dioxide Sparging Efficiency}

Trickling filters and RBCs can also off-gas carbon dioxide under normal operating conditions. The significant air/water interface available to the respiring bacteria allows for the off-gassing of the carbon dioxide produced by the bacteria, as well as that within the water flow which is being sheeted over that surface. At all times, the RBCs in the present study present $50 \%$ of the total unit's surface area, or $465 \mathrm{~m}^{2}$, to the air for gas exchange. 


\section{MATERIALS AND METHODS}

Two separate aquaculture facilities, which used a total of $75 \mathrm{RBCs}$ of the dimensions listed in Table 1, were employed in this study.

Data on the performance of RBCs was collected within two commercial indoor recirculating aquaculture facilities located in eastern Pennsylvania. Both facilities cultured hybrid striped bass over several years under intensive feeding regimens. RBCs were employed in nursery and growout aquaculture systems ranging in total volume from 10,000 liters to 115,000 liters. For this study, 12 separate grow-out systems were studied, each system employing the RBC model described above (RBC10000).

Table 1. Sizing of RBC systems used in this study.

RBC Model

RBC10000
Diameter

$1.22 \mathrm{~m}$
Surface Area

$930 \mathrm{~m}^{2}$

For each of the culture systems observed in this study, the flow rates through the system components permit the tank water volumes to be circulated through the biofilters in an average of 55 minutes. Each system was fed the same feed ( $40 \%$ protein, $16 \%$ fat) which was automatically administered several times daily over a 16-hour light cycle. Un-ionized ammonia concentration was maintained below $0.05 \mathrm{mg} / 1$, with $\mathrm{pH}$ controlled (using automated $\mathrm{NaOH}$ injection) to maintain total ammonia concentration at approximately $3 \mathrm{mg} / \mathrm{l}$.

\section{RBC Nitrification Performance Characteristics}

The efficiency of biofilter operation is usually reported as the nitrification of Total Ammonia Nitrogen (TAN) $/ \mathrm{m}^{2}$ of biofilter surface area/day. This study measures the comparative efficiency of the RBCs by two separate methods.

\section{Feed Input-TAN Calculation Method}

With Study \#1, a theoretical level of TAN production is estimated as a function of the feeding levels. Biofilter efficiency is measured as a function of the removal of that estimated ammonia, thus establishing a steady state TAN concentration within the culture tanks. The daily replacement of $5 \%$ of the water as a function of the recirculation $\%$ of the system was also considered in the removal of ammonia. 
Study \#1 involves eight systems, each with a volume of 150,000 liters, and each utilizing two RBCs. Each RBC has a surface area of $930 \mathrm{~m}^{2}$ to handle the ammonia levels produced by populations of hybrid striped bass being cultured under intensive feeding conditions. Over a five-week period, the average level of feed per day was determined for each of eight production systems (System 1). This level of feeding was mathematically converted to levels of ammonia produced. Using Wheaton et al. (1994), an ammonia production rate of $0.03 \mathrm{~kg}$ TAN $/ \mathrm{kg}$ feed is assigned, and represents the mass of ammonia that must be removed by biofiltration and dilution, in order to maintain equilibrium.

\section{Direct Measurement Method}

Study \#2, carried out in four separate culture systems, each of 77,000 liters (System 2), involves the determination of ammonia levels within the flow of water before and after the individual biofilters, providing a direct measurement of the ammonia removed by filtration (ARF). Samples of water flowing through six RBCs, within four separate aquaculture systems were measured for TAN levels nephelometrically using the LaMotte Smart colorimeter (LaMotte Company, Chestertown, MD, USA), at the influent and effluent ports of the RBC stage. The level of TAN removed during the retention time within the filter is calculated as the difference between influent and effluent concentrations. Considering the measured

Table 2. Operating specifications for each of the two types of culture systems used in this study.

\section{Biofilter Specifications}

\begin{tabular}{|c|c|c|c|c|c|}
\hline & & & & & \\
\hline & $\begin{array}{c}\text { Tank } \\
\text { Design }\end{array}$ & $\begin{array}{l}\text { System } \\
\text { Volume } \\
\text { (liters) }\end{array}$ & $\begin{array}{c}\text { Total } \\
\text { Surface } \\
\text { Area }\left(\mathbf{m}^{2}\right)\end{array}$ & $\begin{array}{c}\text { Total } \\
\text { Specific } \\
\text { Surface } \\
\text { Area }\left(\mathbf{m}^{2} / \mathbf{m}^{3}\right)\end{array}$ & $\begin{array}{c}\text { Total } \\
\text { Flow Rate } \\
\text { (liters/min) }\end{array}$ \\
\hline System 1 & $\begin{array}{l}\text { Cross-Flow } \\
\text { Raceways } \\
\text { (8 systems) }\end{array}$ & $\begin{array}{c}115,000 \\
(2 \text { tanks/ } \\
\text { system })\end{array}$ & $\begin{array}{c}1,860 \\
\text { (2 RBCs) }\end{array}$ & $\begin{array}{c}258 \\
(2 \mathrm{RBCs})\end{array}$ & 1900 \\
\hline System 2 & $\begin{array}{c}\text { Round } \\
\text { Tanks } \\
\text { (4 systems) }\end{array}$ & $\begin{array}{c}77,000 \\
(2 \text { tanks/ } \\
\text { system) }\end{array}$ & $\begin{array}{c}1,860 \\
(2 \mathrm{RBCs})\end{array}$ & $\begin{array}{c}258 \\
(2 \mathrm{RBCs})\end{array}$ & 1,660 \\
\hline
\end{tabular}



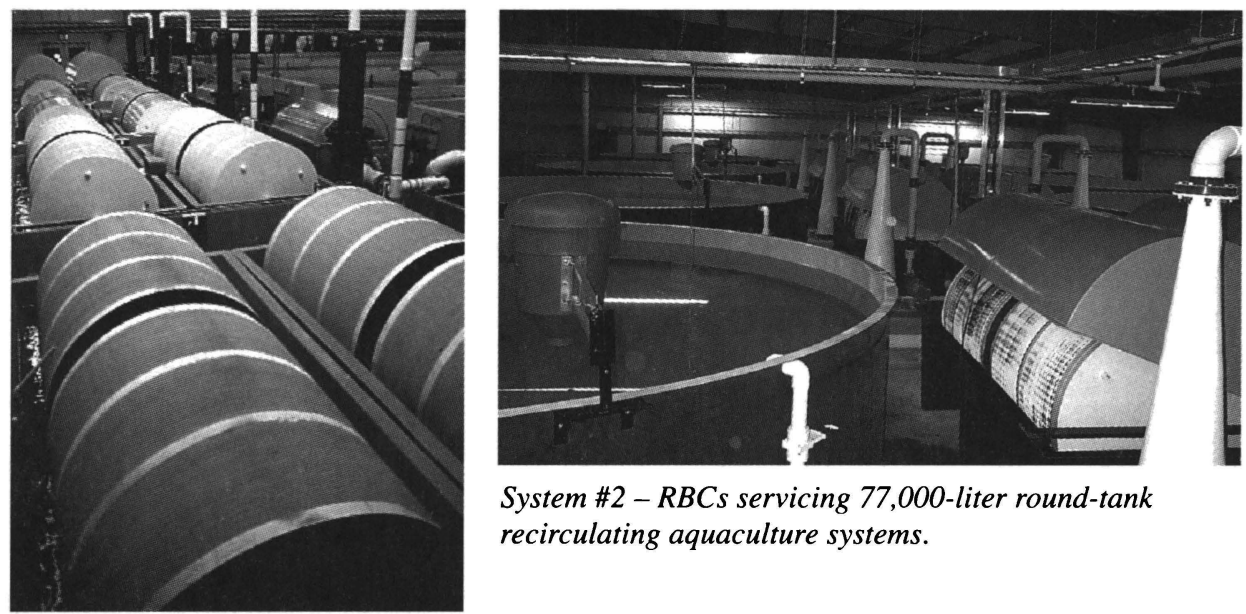

System \#2 - RBCs servicing 77,000-liter round-tank recirculating aquaculture systems.

System \#1-RBCs servicing

115,000-liter cross-flow raceways.

flow rate through the biofilter, and the total surface area of the RBCs, the removal rate in $\mathrm{g} / \mathrm{m}^{2} /$ day is calculated.

\section{Carbon Dioxide Sparging Capacity}

A replicated trial (in situ) was designed to quantify the potential for each $\mathrm{RBC}$ to off-gas carbon dioxide. The most direct measure of the levels of carbon dioxide being removed by the $\mathrm{RBC}$ is by the measurement of the $\mathrm{pH}$ of the water at the influent and the effluent ports of the biofilter. Over a two hour period, six separate $\mathrm{pH}$ measurements were made (using $\mathrm{pH}$ probes able to provide accuracy to 0.01 units) at the influent and effluent ports of two separate biofilters, each receiving 830 liters/minute. The $\mathrm{pH}$ and alkalinity (measured by Standard Methods) of each water sample were used to determine the ambient levels of carbon dioxide in each sample. The difference in the $\mathrm{pH}$ between influent and effluent concentrations provided the level of carbon dioxide sparged by the RBC.

\section{RESULTS}

\section{Ammonia Nitrification Efficiency - Study \#1}

Table 3 lists the average feed levels administered to eight separate culture systems over a five-week period, and the average levels of TAN produced by the fish. With a steady-state situation, the levels of TAN produced, less $5 \%$ removed through water exchange, is assumed to indicate the levels of TAN removed by biofiltration. 
Table 3. Average feed levels administered to eight separate culture systems over a 5-week period, and the average levels of TAN produced by the fish.

Avg Feed/Tank/DayAvg. $\mathrm{Kg}$
TAN Removed $/ \mathrm{m}^{2} /$ Day Grams

\begin{tabular}{c|ccccc|ccccc}
\hline Week \# & 1 & 2 & 3 & 4 & 5 & 1 & 2 & 3 & 4 & 5 \\
\hline Tank \# & & & & & & & & & & \\
1 & 38.4 & 37.1 & 31.7 & 28.1 & 33.0 & 1.43 & 1.09 & 1.17 & 1.03 & 1.22 \\
2 & 33.3 & 18.6 & 24.1 & 36.4 & 43.4 & 1.22 & 0.70 & 0.88 & 1.44 & 1.60 \\
3 & 20.4 & 34.9 & 40.9 & 38.0 & 41.0 & 0.75 & 1.23 & 1.50 & 1.39 & 1.51 \\
4 & 35.0 & 41.0 & 42.5 & 38.2 & 37.3 & 1.28 & 1.50 & 1.56 & 1.40 & 1.37 \\
5 & 36.5 & 40.6 & 12.7 & ----- & 28.6 & 1.34 & 1.49 & 0.47 & ----- & 1.05 \\
6 & 32.8 & 26.8 & 19.4 & 37.6 & 38.0 & 1.21 & 0.99 & 0.71 & 1.37 & 1.40 \\
7 & 27.5 & 35.7 & 35.2 & 30.7 & 48.0 & 1.00 & 1.31 & 1.29 & 1.13 & 1.74 \\
8 & 33.3 & 38.1 & 20.9 & 23.3 & 37.5 & 1.23 & 1.39 & 0.77 & 0.85 & 1.38 \\
\hline
\end{tabular}

$\begin{array}{llllll}\text { Weekly Avg. TAN Removal Rate (g/m²/day) } & 1.18 & 1.21 & 1.04 & 1.23 & 1.41\end{array}$

Overall Average TAN Removal Rate

$1.21 \mathrm{~g} / \mathrm{m}^{2} /$ day

\section{Ammonia Nitrification Efficiency - Study \#2}

Three samples of influent and effluent flow from each of six biofilters were tested for TAN. The average levels of TAN, and the removal rate through the RBCs, is provided in Table 4.

Table 4. Direct measured TAN removal rate.

\begin{tabular}{lccccc} 
Filter \# & $\begin{array}{c}\text { Flow Rate } \\
\text { liters/min }\end{array}$ & $\begin{array}{c}\text { TAN } \\
\text { (Influent) } \\
\text { mg/l }\end{array}$ & $\begin{array}{c}\text { TAN } \\
\text { (Effluent) } \\
\text { mg/l }\end{array}$ & $\begin{array}{c}\text { TAN } \\
\text { Removed } \\
\text { gms/day }\end{array}$ & $\begin{array}{c}\text { Removal } \\
\text { Rate } \\
\text { g/mday }\end{array}$ \\
\hline 1 & 830 & 3.0 & 2.0 & 1195 & 1.3 \\
2 & 828 & 3.4 & 2.6 & 954 & 1.0 \\
3 & 812 & 2.9 & 1.8 & 1286 & 1.4 \\
4 & 815 & 3.1 & 2.2 & 1056 & 1.1 \\
5 & 821 & 2.9 & 1.9 & 1182 & 1.3 \\
6 & 825 & 3.5 & 2.5 & 1236 & 1.3 \\
\hline
\end{tabular}

Avg. TAN removal rate $\left(\mathrm{g} / \mathrm{m}^{2}\right.$-day $) \quad 1.2$

The direct measurement of ammonia influent and effluent levels through each of six separate biofilters demonstrates consistent removal rates with those obtained through feed metabolism calculations. 


\section{Comparative Performance Parameters by Surface Area}

Table 5 demonstrates the comparative nitrification capacity for various types of biofilters:

Table 5. Comparative nitrification capacity for various types of biofilters.

\section{Source}

Submerged Filters (Wheaton et al. 1994)

Bead Filters (Wheaton et al. 1994)

Fluidized Sand Filters (Thomasson 1991)

Rotating Biological Contactor (this study)

\section{Ammonia Removal Rate}

0.3-0.6 gms $/ \mathrm{m}^{2}$-day

$0.20-0.25 \mathrm{gms} / \mathrm{m}^{2}$-day

0.25-0.35 gms $/ \mathrm{m}^{2}$-day

$1.21 \mathrm{gms} / \mathrm{m}^{2}$-day

For fine media biofilters such as fluidized sand or bead filters, volumetric comparisons of nitrification efficiency are often used. By volume, this $\mathrm{RBC}$, with $258 \mathrm{~m}^{2} / \mathrm{m}^{3}$, demonstrates a nitrification rate of $312 \mathrm{gms} / \mathrm{m}^{3}$ day. Tsukuda et al. (1997) estimate nitrification rates for cold-water fluidized sand filters at 150-410 gms/m³ -day. Malone et al. (1993), citing data from Thomasson (1991) and Monaghan et al. (1996), reported ammonia removal rates of $630-800 \mathrm{gms} / \mathrm{m}^{3}$-day in water.

\section{Carbon Dioxide Sparging Capacity}

At six separate intervals, samples of influent and effluent flows in two separate $930 \mathrm{~m}^{2} \mathrm{RBCs}$ were tested, and the average levels for alkalinity, $\mathrm{pH}$, and subsequent carbon dioxide levels were determined. The results are presented in Table 6.

Table 6. Carbon dioxide sparging capacity.

Avg. Avg. Avg. Avg. Alkalinity Influent $\mathrm{CO}_{2}$ Effluent Avg. $\mathrm{CO}_{2}$ Avg. $\mathrm{CO}_{2}$

\begin{tabular}{cccccc}
$(\mathbf{m g} / \mathbf{l})$ & $\mathbf{p H}$ & $(\mathbf{m g} / \mathbf{l})$ & $\mathbf{p H}$ & $(\mathbf{m g} / \mathbf{l})$ & removed \\
\hline 462 & 7.30 & 45 & 7.43 & 36 & $9 \mathrm{mg} / \mathrm{l}$
\end{tabular}

On each pass through the RBC biofilter, the $\mathrm{pH}$ increased by an average of 0.13 units. At the recorded alkalinity (measured colorimetrically), this translates to the sparging of an average of $9 \mathrm{mg} / \mathrm{l}$ of carbon dioxide. Since 
each biofilter is operating at an average flow rate of 830 liters/minute, the $\mathrm{RBC}$ off-gasses an average of $7.47 \mathrm{gms} \mathrm{CO}_{2} /$ minute. This translates to a carbon dioxide removal rate for one RBC of $10.8 \mathrm{~kg}$ of carbon dioxide each day. Timmons et al. (2001) calculates that for every gram of oxygen consumed, 1.38 grams of carbon dioxide is produced. For the systems in this trial, it is estimated (based on direct measurement over extended production cycles) that for every $\mathrm{kg}$ of feed provided, approximately 0.6 $\mathrm{kg}$ of oxygen is consumed.

Therefore, for these systems, receiving an average of $40 \mathrm{~kg}$ of feed daily and consuming an average of $24 \mathrm{~kg}$ /day of oxygen, carbon dioxide is being generated at a rate of approximately $33.1 \mathrm{~kg} /$ day. Each of these systems has two biofilters off-gassing a total of $21.6 \mathrm{~kg} /$ day of carbon dioxide, which is $65 \%$ of the estimated carbon dioxide generated. The systems require additional degassing capabilities to maintain carbon dioxide levels within an acceptable range, but this trial demonstrates that $\mathrm{CO}_{2}$ sparging is a valuable function attributable to the rotating biological contactor.

\section{DISCUSSION}

RBCs have been demonstrated to be one of the most efficient and robust biofilters available for nitrification of aquaculture wastes. They demonstrate extremely high nitrification rates, while providing additional qualifications for self-aeration, off-gassing, and low-head operation. An ammonia removal rate of $1.2 \mathrm{~g} / \mathrm{m}^{2}$-day surpasses all other biofilter configurations cited. With a volumetric nitrification rate of $312 \mathrm{~g} / \mathrm{m}^{3}-$ day, comparisons to fluidized sand filters demonstrate a nearly equal volumetric nitrification rate, and significant superiority in energy efficiency, ease of management, and reliability. Despite slightly increased spatial footprint requirements, the RBC minimizes facility height requisites, which lowers associated operational pumping costs. Staging of appropriately-sized RBCs with multiple and separate culture systems also provides a more versatile alternative than with the use of centralized biofiltration options, such as large fluidized sand filters. The separation of fish populations within independent systems provides valuable biosecurity and sequential rearing advantages.

The present RBC design has eliminated all previous concerns with mechanical durability and reliability of operation. Multiple replicates 
of the latest full-scale iteration of this RBC design were observed in uninterrupted operation at full loading for over three years. No failures of shaft, disassociation of media, or interruption of rotation were observed throughout the three-year trial period. Considering this, in addition to the positive considerations that have always been attributed to this biofilter, the $\mathrm{RBC}$ provides a reliable and effective alternative for consideration in commercial recirculating aquaculture systems.

\section{REFERENCES}

Hochheimer, J.N., and Wheaton, F.W. Biological filters: trickling and $\mathrm{RBC}$ design. In Proceedings of the 2nd International Conference on Recirculating Aquaculture (Roanoke, VA, USA), Flick, G.J., and Rakestraw, T., (Eds.). 1998. Virginia Tech, Blacksburg, VA, USA.

Lewis, W.M., and Buynak, G.L. Evaluation of a Revolving Type Biofilter for use in Recirculating Fish Production and Holding Units. Transactions of the American Fisheries Society, 1976, 105:704-708.

Malone, R.F., Chitta, B.S., and Drennen, D.G. Optimizing Nitrification in Bead Filters for Warmwater Recirculating Systems. In Techniques for Modern Aquaculture. Wang, J.K. (Ed.) 1993. American Society of Agricultural Engineers, St. Joseph, MI, USA.

Miller, G.E., and Libey, G.S. Evaluation of a Trickling Filter in a Recirculating Aquaculture System Containing Channel Catfish. Aquacultural Engineering, 1984, 3:39-57.

Miller, G.E., and Libey, G.S. Evaluation of Three Biological Filters Suitable for Aquaculture Applications. Journal World Aquaculture Society, 1985, 16:158-168.

Monaghan, T.J., Delos Reyes, A.A., Jeansonne, T.M., and Malone, R.F. Effects of Media Size on Nitrification in Fluidized Sand Filters. In World Aquaculture '97 Book of Abstracts 1996. World Aquaculture Society, Baton Rouge, LA, USA.

Rogers, G.L., and Klemetson, S.L. Ammonia Removal in Selected Aquaculture Water Reuse Biofilters. Aquacultural Engineering, 1985, 4:135-154. 
Thomasson, M.P. 1991. Nitrification in Fluidized Bed Sand Filters for use in Recirculating Aquaculture Systems. Unpublished Master's Thesis, LSU, Baton Rouge, LA, USA.

Timmons, M.B., Ebeling J.M., Wheaton F.W., Summerfelt, S.T., and Vinci B.J. 2001. Recirculating Aquaculture Systems. NRAC Publ. No. 01-002. Ithaca, NY, USA.

Tsukuda, S.M., Hankins, J.A., Marshall, C.P., Summerfelt, S.T., Bullock, G.L., and Sawyer, T.K. Effects of Sand Size on Fluidized-bed Biofilter Performance in Cold Water Systems. In Recent Advances in Aquacultural Engineering. Timmons, M.B., and Losordo, T.M. (Eds.). 1997. Northeast Regional Aquacultural Engineering Service, Ithaca, NY, USA.

Van Gorder, S.D., Fritch, J.D. Filtration Techniques for Small-scale Aquaculture in a Closed System. In 34th Annual Conference of the Southeast Association of Fish and Wildlife Agencies. 1980. Nashville, TN, USA.

Wheaton, F.W., Hochheimer, J.N., Kaiser, G.E., Malone, R.F., Kroneș, M.J., Libey, G.S., and Easter, C.C. Nitrification Filter Design Methods. In Aquaculture Water Reuse Systems: Engineering Design and Management. Timmons, M.B., and Losordo, T.M. (Eds.). 1994. Volume 27, Development in Aquaculture and Fisheries Sciences. Elsevier, New York, NY, USA. 